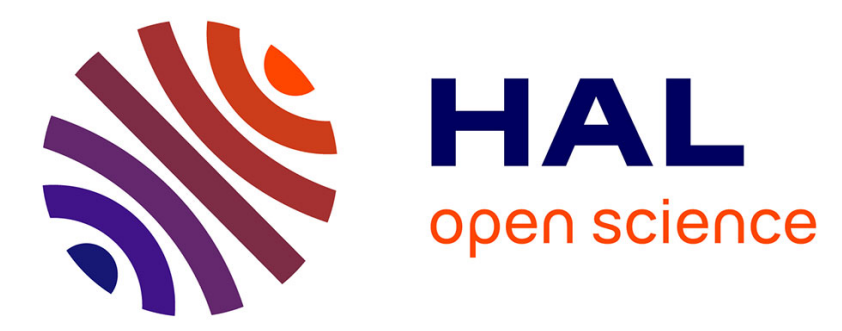

\title{
The ethno-linguistic relationship between smelling and kissing. A Southeast Asian case study
}

Antoinette Schapper

\section{To cite this version:}

Antoinette Schapper. The ethno-linguistic relationship between smelling and kissing. A Southeast Asian case study. Oceanic Linguistics, 2019, 58 (1), pp.92-109. halshs-02935662

\section{HAL Id: halshs-02935662 \\ https://shs.hal.science/halshs-02935662}

Submitted on 10 Sep 2020

HAL is a multi-disciplinary open access archive for the deposit and dissemination of scientific research documents, whether they are published or not. The documents may come from teaching and research institutions in France or abroad, or from public or private research centers.
L'archive ouverte pluridisciplinaire HAL, est destinée au dépôt et à la diffusion de documents scientifiques de niveau recherche, publiés ou non, émanant des établissements d'enseignement et de recherche français ou étrangers, des laboratoires publics ou privés. 


\title{
The ethno-linguistic relationship between smelling and kissing.
} A Southeast Asian case study.

\author{
Antoinette Schapper
}

This paper investigates smell/kiss colexification, the lexical semantic association of transitive verbs of smelling with verbs expressing certain types of conventionalised gestures of greeting and/or affection (i.e., kissing). Whilst found sporadically in the languages of the world, smell/kiss colexification is common in languages of all families of Southeast Asia. The prevalence of the lexical association reflects an ancient, endemic Southeast Asian practice in which kissing involves the nose, rather than the mouth, as the primary organ. This study demonstrates the potential of lexical semantic typology to contribute to identifying linguistic areas and cultural practices shared across them.

\section{Introduction 1}

Within the domain of perception, the semantic extension of verbs of seeing and hearing to additional meanings of understanding, thinking and reasoning has been discussed by multiple scholars. By contrast, little is known about semantic extensions of verbs of olfactory perception, i.e. verbs of smelling. This paper investigates what other meanings are associated with verbs of smelling cross-linguistically beyond the field of perception, identifying a recurrent lexical semantic association between smelling and kissing across Southeast Asia. Smell/kiss colexification, as I shall refer to this lexical semantic association, reflects a cultural practice widespread across Southeast Asia in which conventionalised gestures expressing greeting and/or affection (i.e., kissing) involve an olfactory gesture (i.e., smelling, sniffing).

A large geographical area with significant ethno-linguistic diversity, Southeast Asia extends on the Asian mainland from southern China to the Malay Peninsula, and in the insular regions from the Andaman and Nicobar Islands in the eastern part of the Bay of Bengal through Indonesia and the Philippines before terminating at the western extreme of New Guinea. The area is home to speakers of languages of the Sino-Tibetan, Hmong-Mien, Tai-Kadai, Austroasiatic and Austronesian families. In Mainland Southeast Asia, neighbouring languages across these families share typological features to such an extent that the region has been characterised as 'the ultimate Sprachbund' (Dahl 2008:218). The Austronesian languages that dominate Island Southeast Asia are at a greater typological distance to the languages of the Mainland Southeast Asia, but both, nonetheless, have been shown to share an array of linguistic features that are the

\footnotetext{
${ }^{1}$ This paper was written up under the auspices of a KNAW Gonda Fellowship hosted at the IIAS, Leiden University. Research funding came from the Netherlands Organisation for Scientific Research VENI project "The evolution of the lexicon. Explorations in lexical stability, semantic shift and borrowing in a Papuan language family”, the Volkswagen Stiftung DoBeS project “Aru languages documentation”, and the Australian Research Council project (ARC, DP180100893) "Waves of words". I first began to pursue this topic as part of a visiting research fellowship at the Department of Linguistic and Cultural Evolution of the Max Planck Institute for the Science of Human History in 2016. Many thanks to Russell Gray for the opportunity to spend time in Jena. During that time, Laurie Reid and David Gil endured many possibly uncomfortable - discussions on kissing practices in Southeast Asia. Both Yedda Palemeq and Elizabeth Zeitoun were extremely helpful in explaining and looking at sources on the Formosan groups for me - thanks so much! Useful comments on an earlier draft of this paper were provided by Sander Adelaar and Alexandre François. A more historically-oriented version of this paper was presented at the 7th International Conference on Austro-Asiatic Linguistics at Christian Albrechts University in Kiel, on September 29 - October 1, 2017. I am thankful to the audience for tolerating and entertaining a non-expert enthusiast such as myself. Especial thanks go to Paul Sidwell, Mattias Jenny and Felix Rau for their interest and many helpful suggestions, and to John Peterson and Piers Vitebsky for sharing their Munda perspective. All errors are my own.
} 
result of diffusion through contact and/or substrate (Urban 2010, Gil 2015, Matisoff 1992). I show that smell/kiss colexification is another typological feature whose distribution unites the whole of Southeast Asia into a single linguistic area.

More than that, this study demonstrates the significant insights that lexical typology can provide into processes of socio-historical diffusion of innovation in cultural practice over geographic areas. Spitzer (1947:2 quoted by Evans 2010) points out that 'of all linguistic branches, it is in semantics that the changes due to cultural development can best be seen at work, for "meaning" is the best barometer of cultural climate'. Since words represent concepts and are thus closely tied to cognitive representations, the cross-linguistic study of lexical meaning can be particularly valuable in charting cultural variation, but remains little explored by typologists.

\section{World-wide colexification patterns of 'smell' verbs}

Colexification, a term coined by François (2008), refers to a situation in which two or more meanings are covered in a language by one and the same lexical item. Colexification implies a conceptual relationship between lexemes, but does not distinguish between polysemy or semantic vagueness, nor does it make any comment on the diachronic relationship between the meanings taken in by a lexeme (see Urban 2012: 99ff. for a discussion of issues in typological comparison of the lexicon).

In this section, I use data from the CLICS Database of Cross-linguistic Colexifications (List et al. 2014) to establish what meanings colexify with verbs of smelling crosslinguistically. ${ }^{2}$ CLICS contains 221 different language varieties covering 64 different language families, covering 1,280 different concepts. The data underlying CLICS is geographically biased towards the Caucasus, Europe and South America. So, whilst the CLICS sample is not suitable for statistical generalisations, it can be used to make some preliminary observations about the world-wide occurrence of colexification of verbs of smelling. In order to rule out accidental homonymy, I only discuss colexifications that are found in more than one language family (as recommended by List et al. 2014).

The target meanings that I look at are the following transitive verbs of smelling:

a. to smell (transitive, agent-oriented): 'to inhale through one's nose in order to smell something' (WOLD/ICD Meaning 15.212, glossed 'to sniff')

b. to smell (transitive, experience-oriented): 'to notice a particular smell' (WOLD/ICD Meaning 15.22, glossed ‘to smell(2)')

In the database, these meanings are frequently colexified with one or more other meanings; 101 languages ${ }^{3}$ display colexifications which are recurrent (ie., are found in more than one language and in more than one language family). The vast majority of languages (83 of 101 languages) colexify these meanings exclusively with other meanings within the domain of olfaction, as follows: (i) colexification of the two target meanings, to smell (transitive, agent-oriented, i.e., 'to inhale through one's nose in order to smell something') and to smell (transitive, experienceroriented, i.e., 'to notice a particular smell'), a pattern which is found in 53 languages; (ii) 17 languages colexify ‘to smell (transitive, experiencer-oriented)' with 'to smell (intransitive, i.e.,

\footnotetext{
${ }^{2}$ As this paper was going to press a new version of CLICS was released (CLICS 2.0: List et al. 2018). The distribution of smell/kiss colexification given in that extended database is consistent with the picture from CLICS 1.0.

${ }^{3}$ This number becomes 108, if we count language varieties rather than languages.
} 
'to have a particular smell'), ${ }^{4}$; (iii) 7 languages colexify 'to smell (transitive, agent-oriented)' with 'to smell (intransitive)', and; (iv) 6 languages colexify all three meanings, i.e., 'to smell (transitive, agent-oriented)', 'to smell (transitive, experiencer-oriented)', and 'to smell (intransitive)'.

The remaining 17 languages (18 language varieties) show a diverse range of colexification patterns that extend beyond the domain of olfaction (Table 1). Ten of these languages show colexification of smell verbs with other perceptual (i.e., intrafield) meanings, patterns which have been extensively discussed for diverse languages the world over (e.g., Meeusen 1975, Viberg 1983, Sweetser 1990, Evans \& Wilkins 2000, Vanhove 2008). Outside of the domain of perception, the CLICS database documents only two (transfield) colexification patterns for transitive verbs of smelling. The first is colexification of 'to smell (transitive, agentoriented)'/'to smell (transitive, experiencer-oriented)' with 'to breathe', a semantic association dealt with (particularly in the nominal domain) by François (2008). The second pattern involves the colexification of 'to smell (transitive, agent-oriented)'/'to kiss'. This colexification is found in two sets of languages in the CLICS database: (i) Guaraní varieties and Sanapaná, neighbouring languages spoken in the central South American countries, Paraguay and Bolivia, and (ii) the Austronesian languages, Indonesian spoken area in Island Southeast Asia, and Rapa spoken in Polynesia, as well as White Hmong, a Hmong-Mien language spoken on Mainland Southeast Asia.

The lexical semantic association of smelling and kissing is not one that has been discussed in any typological literature that I am aware of. Present in barely 5\% of the CLICS sample, smell/kiss colexification - as I shall refer to it henceforth - on the surface appears to be a very minor phenomenon in the world's languages. The findings from this cross-linguistic sample are, however, suggestive of an areal clustering of smell/kiss colexification over Southeast Asia and Oceania. Indeed, I will show in this paper that smell/kiss colexification is a widespread lexical semantic association in that part of the world, reflecting a shared cultural practice in which kissing involves an olfactory gesture.

\section{The Southeast Asian kiss in cross-cultural perspective}

To understand the basis for the synchronic lexical association of verbs of smelling and kissing an appreciation of some of the variation in kissing practices world-wide is valuable. The cultural universality of kissing has been a topic of discussion among anthropologists and those studying human sociality and behaviour (e.g., Eibl-Eibesfeldt 1972, Wlodarski and Dunbar 2014, Danesi 2013, Ford \& Beach 1951, Gregersen 1983, Kirschenbaum 2011). The definitions used by scholars range from encompassing extremely broad-range of gestures (e.g., 'the rubbing or patting of the arm, breasts, or stomachs to striking one's face or the feet of another' Kirschenbaum 2011) to a very narrow set of gestures (e.g., Jankowiak et al. 2015 'lip-to-lip contact that may or may not be prolonged'). For the purposes of this paper, I use the following cross-cultural definition of a kiss:

(2) A conventionalised gesture expressing greeting and/or affection in which there is intentional touching or near-touching of one's face or part thereof to the face or body(part) of another person.

\footnotetext{
${ }^{4}$ In WOLD/ICD series, this is Meaning 15.21: to smell(1).
} 
Table 1: Colexification of transitive smell verbs with non-smell meanings $\dagger$

\begin{tabular}{|c|c|c|c|c|c|c|c|c|c|}
\hline & & $\begin{array}{l}\text { to smell } \\
\text { (transitive, } \\
\text { agentive) }\end{array}$ & $\begin{array}{l}\text { to smell } \\
\text { (transitive, } \\
\text { experiencer) }\end{array}$ & $\begin{array}{l}\text { to smell } \\
\text { (intransitive) }\end{array}$ & to feel & to hear & to taste & to kiss & to breathe \\
\hline Aguaruna & Jivaroan & & dikapit & & dikapit & & & & \\
\hline Carib & Carib & & eta & & & eta & & & \\
\hline French & Indo-European & & sentir & sentir & sentir & & sentir & & \\
\hline Guaraní, Eastern Bolivian & Tupi & $\tilde{e} t u$ & $\tilde{e} t u$ & & & & & $\tilde{e} t u$ & \\
\hline Guaraní, Paraguayan & Tupi & & $a^{n} d u$, hetũ & & $a^{n} d u$ & & & hetũ & \\
\hline Indonesian & Austronesian & & mencium $\ddagger$ & & & & & mencium & \\
\hline Italian & Indo-European & annusare & annusare, sentire & & sentire & sentire & & & \\
\hline Kaingang & Macro-Ge & & $m \tilde{\varepsilon} \eta$ & & & $m \tilde{\varepsilon} \eta$ & $m \tilde{\varepsilon} \eta$ & & \\
\hline Lengua & Mascoian & & liyaiyi & & linaiyi & liyaiyi & liyaiyi & & \\
\hline Mari, Meadow & Uralic & & $\check{s} \check{s i}$ '̌̌aš & & $\check{s} \bar{s}^{\prime} \check{z} a \check{s}$ & & & & \\
\hline Miao, White & Hmong-Mien & hnia & hnov & & hnov & hnov & & hnia & \\
\hline Movima & isolate & & payesna & & payesna & & & & \\
\hline Rapa & Austronesian & & hoyi & & & & & hoyi & \\
\hline Rotuman & Austronesian & huya & huya & & & & & & huya \\
\hline Sanapaná (Standard) & Mascoian & & antikhanki & & & & & antikhanki & \\
\hline Seselwa Creole French & Creole & & santi & santi & santi & & & & \\
\hline Siona & Tucanoan & & yi?ehi & yi?ehi & & & & & yi?ehi \\
\hline Welsh & Indo-European & synhwyro & synhwyro, clywed & arogleuo & synhwyro & clywed & & & \\
\hline
\end{tabular}

$\dagger$ I have excluded Mandarin Chinese from this list. The CLICS database strips off tonal indications using numbers that are present in the WOLD/ICD databases. The loss of this marking means that CLICS renders Mandarin Chinese 'to smell (transitive, agent-oriented)' and 'to kiss' as wen, whereas the original WOLD database given wen2 'to smell (transitive, agent-oriented)' and wen3 'to kiss'.

¥ I retain the classification presented in CLICS for the Indonesian verb even though it does not seem entirely correct to me. According to my understanding of mencium, it is used as a transitive verb 'smell' with both agentive and experiencer meanings. For instance, mencium in a sentence such as Banyak orang memiliki kebiasaan mencium makanan sebelum dimakan 'Many people have the habit of smelling food before eating it' has, to my mind, a clearly agentive meaning. 
In order to prevent any intimate touching of another person from qualifying as a kiss, this definition requires that the kisser's face or a part of the kisser's face be used in the act of kissing. At the same time, this definition does not require that kissing be romantic/sexual, but allows for a kiss to be used in non-sexual contexts, recognising that within a culture kissing be performed in different ways to express different kinds of intimacy between the kisser and kissee.

Throughout this paper, I will use 'kiss' with the meaning in (2) as a comparative concept in the sense of Haspelmath $(2007,2010)$. That is, 'kiss' is to be understood here as a metalanguage gloss for comparing across language-culture systems. Such a definition is used strictly as a convenient cover term for the purposes of gaining a cross-linguistic point of view.

A topic of particular importance for this paper, but largely unexplored in the literature, is the distribution of variation in human kissing as to which part of the face is primarily engaged by the kisser. Based on a survey of the literature, two primary types of kiss can be identified world-wide: (i) a mouth-kiss, where the kisser's primary instrument of kissing is the mouth, with lips being laid on or near the kissee and; (ii) a smell-kiss (also known as a sniff-kiss, olfactory kiss, nose-kiss, noserubbing, Oceanic kiss, Eskimo kiss) where the kisser's primary instrument of kissing is the nose, through which air may be drawn as part of the kiss. These two are by no means mutually exclusive, as we shall see in the following section.

In Western descriptions and travel accounts of Southeast Asian peoples from the early $20^{\text {th }}$ century and before, the smell-kiss is frequently remarked upon. Authors repeatedly observe that olfactory gestures of sniffing, breathing in through the nose or, more rarely, rubbing noses are involved in the act of kissing. On Mainland Southeast Asia, we find descriptions of smell kissing across all the major ethnolinguistic groups. For the dominant Tai-Kadai speaking groups of Thai and Laos, descriptions such as the following are found in the literature:

The Siamese kiss with their noses, by pressing them against their friends', and saying, "Very fragrant, very fragrant!” while they take long, satisfied sniffs. (Cort 1886: 170)

Laotians [...] do not practice kissing, at least not in the European way. They rub their nose against the skin of their children or their women by sniffing in a more or less noisy way. (Reinach 1911: 172)

Similar descriptions of smell kissing are recorded for the Tibeto-Burman language groups of Southeast Asia, as in:

When the Burmese kiss, they inhale at the same time, making it look as if they are smelling, an action that they call nam-cut-si or to suck in (cut) a smell (nam). (Bastian 1866 [2004]: 132):

[The tribes' of Chittagong] mode of kissing is strange: instead of pressing lip to lip, they apply the mouth and nose to the cheek, and give a strong inhalation. In their language they do not say, “Give me a kiss;” but they say, "Smell me.” (Lewin 1869: 46)

Disparate Austroasiatic speaking groups in Southeast Asia are also described as practicing the smellkiss. For example: 
Cambodians are ignorant of the kiss. They do not kiss, they smell, they sniff. The mother breathes in [the scent of] her child. Lovers do not take in full lips, but full nostrils. (Bourdet 1912: 481)

Mothers [in the Nicobar Islands] will naturally often kiss their babies, but their "kissing" [...] consists in embracing and rubbing faces and in sniffing the child. (Whitehead 1914: 122)

Across Austronesian-speaking groups of Island Southeast Asia there is again a recurrent association between smelling and kissing. For example:

With Malays to kiss is, ordinarily, to put face close to face and draw in the breath through the nose as one smells a flower. (Clifford \& Swettenham 1894: 363)

...[amongst the Negritos of the Philippines] kissing - perhaps I should say smelling for the Pygmy kiss [...] is a kind of a sniff and a snuff made while the nose is on contact with the cheek or other part of the body but never on the lips,... (Garvan 1964: 140)

Whilst these descriptions highlight the 'otherness' of Southeast Asian kissing practices from a western perspective, it is nonetheless clear that the authors recognise the functional equivalence of the smellkiss with the European mouth-kiss.

\section{Smell/kiss colexification in Southeast Asia}

Relatively few ethnographic sources for Southeast Asia describe kissing practices and often not in relation to specific ethno-linguistic groups, tending rather to make generalisations over the dominant groups of nation states. As such, it is difficult to reconstruct from these ethnographic sources how widespread smell-kissing is. The quotes in the previous section, however, make clear that in Southeast Asia, having the nose rather than the mouth as the organ of kissing means that kissing is in its essence a kind of smelling. Indeed, the presence of a smell-kiss in a culture's practice frequently correlates with a language showing identity between the lexeme used to describe this conventionalised gesture and a verb to smell. In short, the distribution of smell-kissing in SEA can be studied by proxy through smell/kiss colexification.

The findings from the cross-linguistic sample (section 2) establish that smell/kiss colexification is rare in the world's languages outside Southeast Asia and Oceania. In this section I use the presence of smell/kiss colexification to assess the extent of smell-kissing and whether its distribution shows areal clusterings within Southeast Asia. To answer these questions, I have constructed an in-depth, but largely opportunistic, sample of Southeast languages (see Appendix), as follows:

(i) data for Austroasiatic from the Mon-Khmer comparative dictionary (http://sealang.net/monkhmer/dictionary/) and for the Munda languages, the other major branch of Austroasiatic, from the Munda Languages Project database (http://sealang.net/munda/database/) and the Munda Dictionary Project (http://www.southasiabibliography.de/), with supplementary data from extant dictionaries; and for the Munda languages, the other major branch of Austroasiatic, from the Munda Languages Project database (http://sealang.net/munda/database/) and the Munda Dictionary Project (http://www.southasiabibliography.de/), with supplementary data from extant dictionaries;

(ii) data for Tai-Kadai languages from Intercontinental Dictionary Series (where TK languages are well-represented) with supplementary materials from extant dictionaries; 
(iii) data for Sino-Tibetan languages from The Sino-Tibetan Etymological Dictionary and Thesaurus (http://stedt.berkeley.edu/) with supplementary materials from extant dictionaries;

(iv) data for Hmong-Mien languages from the Intercontinental Dictionary Series and from the World Loan Word Database;

(v) data for Austronesian languages in Taiwan ('Formosan languages') and across Island Southeast Asia from extant dictionaries. ${ }^{5}$

The data was collected from these sources, in the first instance, by searching for glosses 'smell/sniff' and 'kiss'. The lexemes with these glosses were then compared and coded as to identity. For instance, the Austroasiatic languages Katu cem and Brao muk are presented in the Mon-Khmer comparative dictionary with glosses of both 'smell' and 'kiss' and accordingly are coded as having smell/kiss colexification. In the World Loanword Database, White Hmong hnia is given twice under the meanings 'to sniff' and 'to kiss ${ }^{6}$ and is similarly counted as exhibiting smell/kiss colexification.

In some cases, lexicographers provide more information on the kind of kiss that is meant. For instance, Headley (1997) defines Khmer ksəit with 'to puff; to breathe in, sniff; to kiss (in the Cambodian manner by placing the nose against the cheek and sniffing'. Not all authors use the gloss 'kiss', but we can still perceive an identification of smelling with the cross-cultural definition of kiss established in section 3. For example, Mon chзy is defined by Shorto (1962) with 'to sniff, smell, embrace in token of affection'. The identity of an olfaction verb and a verb encoding a gesture expressing affection here is taken to indicate that Mon culture historically included a smell-kiss. ${ }^{7}$

In a small number of languages, there is not complete identity between 'kiss' and 'smell' in a language, but a productive morphological process can be seen to relate the two meanings together. In Arta, for example, the meanings 'smell' and 'kiss' are coded with one and the same verb root angut, but with different applicative suffixes, as in (3).

Arta (Austronesian, Philippines; Kimoto 2017).

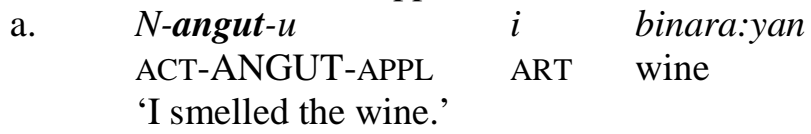

\footnotetext{
${ }^{5}$ I do not include Oceanic languages in the Austronesian sample. Oceanic languages are a numerically very significant, but ultimately form only a single - albeit well-defined - subgroup of the Malayo-Polynesian languages (Austronesian language subgroups spoken outside Taiwan). It seems certain that the speakers of Proto-Oceanic already practiced the smell-kiss; smell/kiss colexification is widespread in Oceanic languages, especially in Polynesian languages (see POLLEX database, Greenhill \& Clark 2011), a low-level subgroup of Oceanic where influence from Melanesian has been relatively limited (cf. Pawley 2007). The Oceanic subgroup represents an important testing ground for Papuan versus Malayo-Polynesian features. A future study of smellkissing in these languages will provide an interesting perspective on the multiple Papuan substrates in Oceania.

${ }^{6}$ In WOLD/ICD to kiss is Meaning 16.29. Unlike for to sniff/Meaning 15.212 and to smell(2)/Meaning 15.22, there is no 'typical context' given for to kiss, perhaps reflecting an editorial recognition of cross-cultural variation in kissing.

${ }^{7}$ Kissing practices do change over time, creating changes in the reference of words glossed with 'kiss'. In Malay/Indonesian, for instance, cium 'smell, kiss' traditionally only refers to a smell-kiss (cf. early dictionary definitions such as by Crawfurd (1852) 'smell, sniff; kiss, salute by smelling'), but has with increasing Western influence been extended to the mouth-kiss in the modern language. Across much of Indonesia today, the mouthkiss still remains either unknown or clearly lies outside local customs. For Bali, Kalyanaraman (1970: 305) writes 'the Balinese abhor mouth-to-mouth kissing; tender 'smelling' of the head and of the cheeks is the approved method of showing affection.' Himmelmann (2001: 111) similarly notes of the Tomini-Tolitoli speakers of northern Sulawesi that he worked with that 'kissing as a lip-related action was a concept completely foreign to practically all contributors', noting that 'some of the items listed here ... can also be glossed with English 'kiss' ... in the sense that 'smelling at' someone's cheek or hand may express affection or respect.'
} 


\section{b. $\quad$ Angut-an=tatawmakabba:t $=m u$ \\ ANGUT-APPL $=$ if.like $=2$ SG \\ 'I'll kiss you if you like.'}

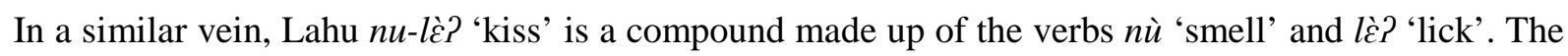
inclusion of a smell lexeme here indicates that an olfactory gesture is part of Lahu kissing and it is accordingly treated as an instantiation of the smell/kiss colexification pattern. These are classified as instances of subcolexification (Schapper et al. 2016, or 'loose colexification' in François' 2008 terms). ${ }^{8}$

Using these coding principles, we find that colexification of 'smell' and 'kiss' is distributed across Southeast Asia as set out in Map 1. Smell/kiss colexification occurs exclusively in Mon-Khmer languages of the Austroasiatic family, but is not attested in the Munda languages, a branch of Austroasiastic whose speakers migrated out of Southeast Asia into the Indian subcontinent. In the same vein, the Sino-Tibetan, Tai-Kadai, Hmong-Mien families who have members both within Southeast Asia and beyond the northern fringe of the area display smell/kiss colexification almost exclusively in languages which the Southeast Asian area. ${ }^{9}$ Turning to Austronesian languages, I also do not find the pattern in the languages of Taiwan, the Austronesian homeland, but across Southeast Asia from the Philippines southwards smell-kiss colexification is found sporadically. The geographical distribution of smell/kiss colexification is thus confirmed to be a strictly Southeast Asian phenomenon.

As already discussed, the absence of smell/kiss colexification does not entail the absence of a smellkiss in an ethno-linguistic group's cultural practice. So how do we know that smell-kissing is not present outside of Southeast Asia albeit without smell/kiss colexification? The answer to this question is two-fold. First, for groups outside of Southeast Asia I have been unable to identify any ethnographic reports of smell-kissing such as the numerous ones found for within Southeast Asia, some of which were presented in section 3. Yedda Palemeq (pers. comm.) conducted a search of $17^{\text {th }}$ to 19 th century Chinese historical documents about Taiwan for me and was unable to locate any reference, direct or indirect, to a practice of smell-kissing. Elizabeth Zeitoun (pers. comm.) confirmed the absence of smell-kissing amongst the Austronesian aborigines of Taiwan on the basis of her many years of field observations. For the Munda, I was similarly unable to locate any descriptions of smell-kissing in published historical materials; field researchers John Petersen (pers. comm.) and Piers Vitebsky (pers. comm.) corroborated the lack of the smell-kiss amongst the Munda. We would expect, if the smellkiss was present to the north of Southeast Asia that the practice would have attracted some attention in the ethnographic literature and fieldworkers the way it has in Southeast Asia.

\footnotetext{
${ }^{8}$ Not counted as subcolexification are instances of near-identity of roots for 'smell' and 'kiss' where the morphological relationship between verbs is not understood. An example of this is Sumi $m n a$ 'smell' and $m m a$ 'kiss' (Amos Teo pers. comm.), which look like they are related in some way but the $\mathrm{n} \sim \mathrm{m}$ alternation is not known to be a part of productive let alone historical morphological process. Great Andamanese is another, albeit

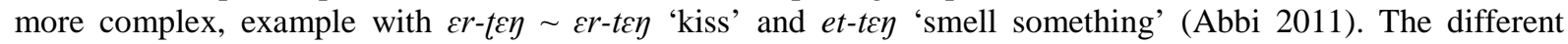
prefixes appear to reflect different lexical classes and could mean that the meanings are in a relationship of subcolexification. However, there is a difference between the realisation of the roots with the former begins with retroflex or a dental while the latter begins with a dental. Retroflexion may have been introduced by influence from South Asian languages, thereby creating a weak distinction between these originally possibly identical roots. Circumstantial support for this hypothesis comes from ethnographic records which report the presence of smell-kissing in the Andaman Islands (e.g., 'they sniff for kissing' NA 1908: 8).

${ }^{9}$ The one exception I have found is the Sino-Tibetan language Limbu spoken in Eastern Nepal. Limbu has smell-kiss colexification, but I have not found any report of smell-kissing amongst them. In this case, the colexification may therefore represent accidental homophony rather than a motivated semantic association.
} 


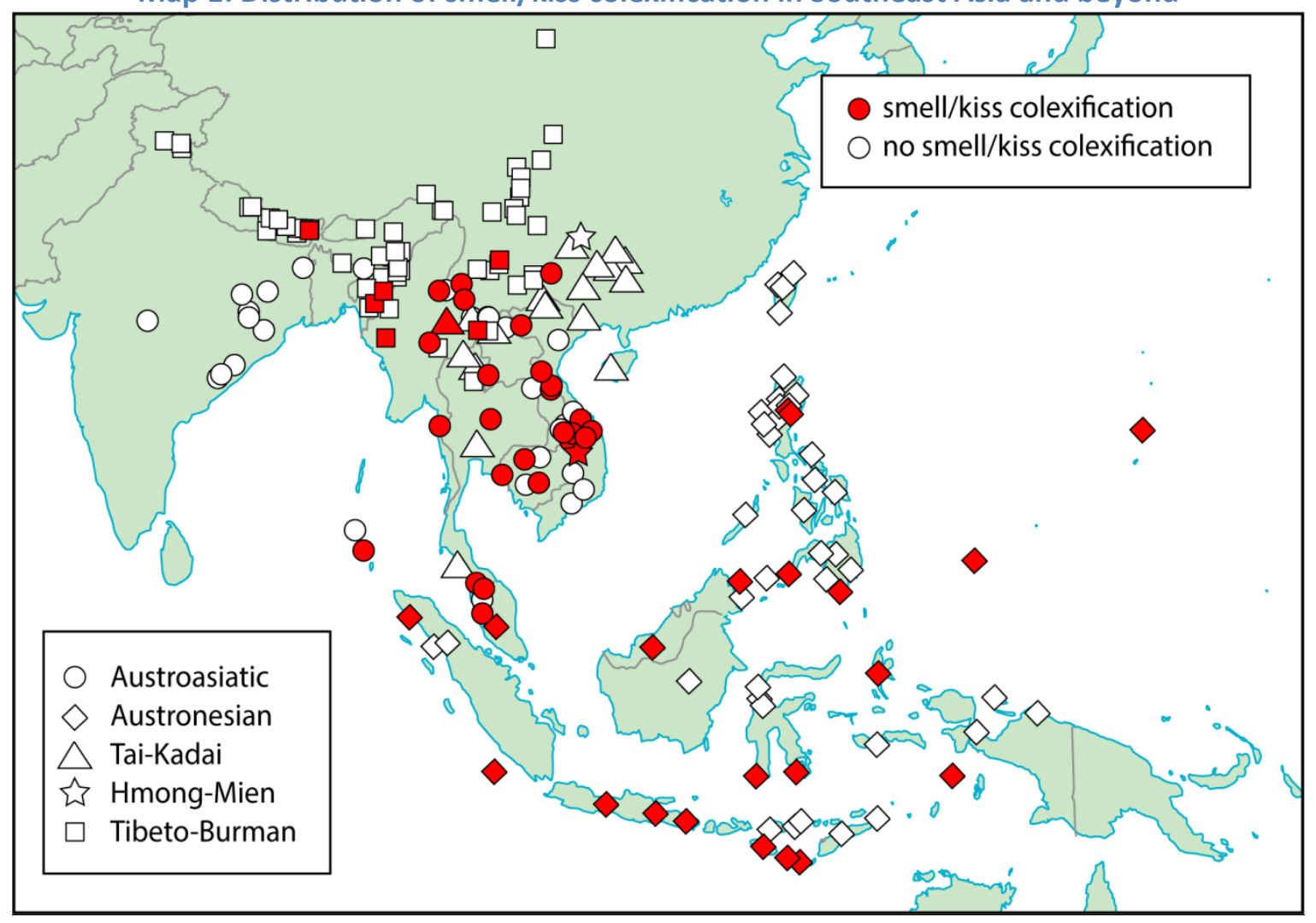

The second reason to doubt the presence of the smell-kiss in the absence of smell/kiss colexification is the existence of another colexification pattern, suck/kiss colexification, that is associated with a mouth-kiss. Both suck/kiss colexification and smell/kiss colexification are found in six languages in the current sample. For four of these the source materials provide sufficient detail such that it is clear that the item colexifying 'suck' and 'kiss' invariably refers to a mouth kiss, while the item colexifying 'suck' and 'kiss' refers to a smell-kiss:

Languages with smell/kiss and suck/kiss colexification

Shan nom1 'smell, kiss with nose', tsup2 'suck, kiss with lips'

Palauan melúngel 'smell, kiss with nose', melmótm 'suck, kiss someone’s mouth'

Mapun $\bar{u} k$ 'smell, kiss', sassop 'suck, kiss on lips'

Makassarese $m u$ 'musu' 'to suck on something with puckered lips, suck the contents out of something, kiss in the European way', njo'njo' 'to drink from something with puckered lips, drink in the manner of an animal, sip, suckle as of a child, kiss as Europeans do with puckered lips', ara' 'to smell (something), kiss'

Kensiu Pэn 'smell, kiss', fot 'suck, kiss'

Paliu mpuit.33 'smell, kiss', hut.33 'suck, kiss'

Despite some overlap in the distributions of smell/kiss and suck/kiss colexification, suck/kiss colexification is concentrated at the northern perimeter of the Southeast Asian linguistic area (Map 2). Languages with suck/kiss colexification belong overwhelming to the Sino-Tibetan and Tai-Kadai families, both of whose origins lie outside of the core Southeast Asian area. The presence of suck/kiss colexification indicates that it is the mouth-kiss rather than the smell-kiss which is present here. 
Map 2: Distribution of smell/kiss colexification and suck/kiss colexification in languages of

Southeast Asia and beyond

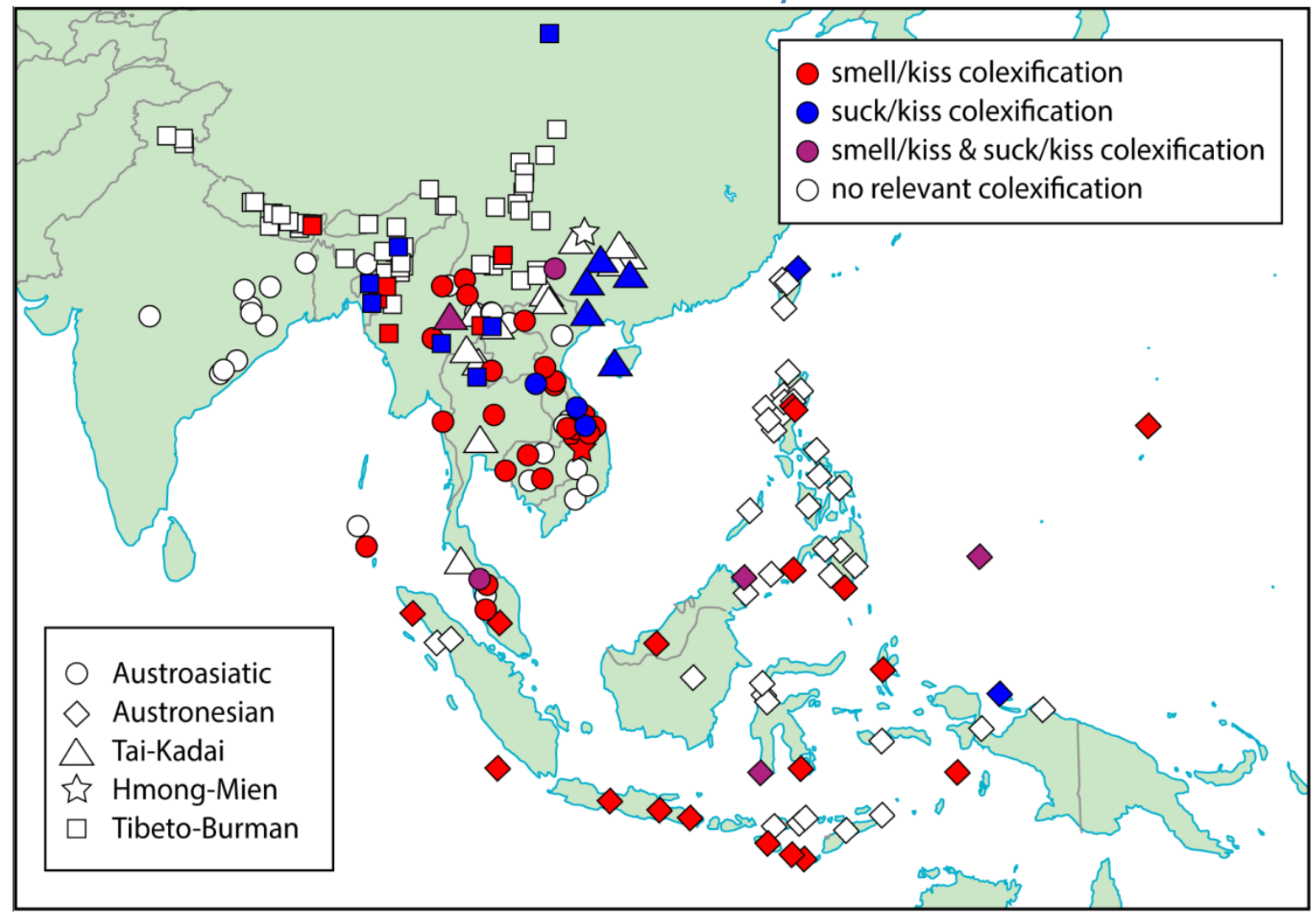

This striking concentration of smell/kiss colexification across languages of Southeast Asia and its absence from the adjacent region requires explanation. The visible centre of gravity for smell/kiss colexification is in the Mon-Khmer branch of Austroasiastic, the oldest retrievable language family of the Southeast Asian Mainland. Through contact with speakers of Austroasiatic languages and shift from their languages, it seems clear that smell/kiss colexification sporadically entered languages of the Sino-Tibetan, Tai-Kadai and Hmong-Mien families as their speakers dispersed southwards into Southeast Asia. The acquisition of smell/kiss colexification by these languages would appear in turn to reflect an adoption of an in-situ cultural practice of smell-kissing from earlier populations, such as the Austroasiatic peoples.

The appearance of smell/kiss colexification in the Malayo-Polynesian languages of Insular Southeast Asia suggests a more complex historical scenario. Austroasiatic influence on these Austronesian languages has not been definitively detected; Adelaar (1995) observed a small number of shared features between the Land Dayak languages of western Borneo and languages of the Aslian branch of Austroasiatic, but was non-committal about the historical source of the similarities. However, smell/kiss colexification is not limited to Borneo, but is found across the full sweep of Austronesian languages outside of Taiwan. Blust \& Trussel (ongoing) observe that Proto-Austronesian *Sajek can only be reconstructed as an olfactory verb meaning 'to smell (transitive)', but in Proto-MalayoPolynesian, the daughter of Proto-Austronesian spoken in the northern Philippines, *hajek acquired an additional meaning referring to the smell-kiss of Malayo-Polynesian-speaking peoples. Given the absence of well-established Austroasiatic influence on the early Malayo-Polynesian peoples, smellkissing is most likely then an ancient areal feature which was shared across Mainland and Island Southeast Asia before the Malayo-Polynesian dispersal. 


\section{Comparing kisses}

If we look up 'kiss' in the dictionaries of two languages, how can we be certain that we are comparing like with like? Can a smell-kiss really be compared to a mouth-kiss, or are they entirely different, unequatable actions? In this section I discuss the issue of comparability of the lexico-semantic data and suggest that there is reason for confidence that a comparative work such as the present one does indeed rest on firm typological foundations.

Colexification studies do not presuppose exact semantic equivalence between compared items. Rather, in the approach as developed by François (2008), there must only be an overlap in the extensional range encompassed by the lexical semantics of the compared lexical items. In comparing translational equivalents in dictionaries (i.e., dictionary glosses), I rely on a perceived similarity by the lexicographer between the gesture in the target language and the gloss in the translation language. That is, I assume the gloss to be a shorthand for the metalanguage definition of 'kiss' as given in (2) without presuming what part of the face is involved in the kiss gesture. This is not fool-proof, but if the terms glossed as 'kiss' in dictionaries were semantically so incompatible with each other as to make cross-linguistic comparison impossible, we would not expect the neat areal distributions we find. Without brushing off the potential of glosses to bias the analysis made of an object language, it is hard to believe that the recurrent association of the same roots with the glosses 'smell' and 'kiss' across SEA as well as 'suck' and 'kiss' to the north of SEA does not capture a real point of ethno-linguistic diversity in cultural practice.

A possible point of contention is that- as two reviewers of this paper argued- the investigated verbs glossed as 'kiss' cannot be analysed as evoking the same meaning because there is no cross-culturally establishable phenomenon that corresponds to the comparative concept 'kiss' that I give in (2). In other words, it could be argued that a smell-kiss is not a mouth-kiss and the two should not be united into a superordinate 'kiss' category. The denial of a comparative concept 'kiss' is obviously not supported by descriptions such as those given in section 3 where Westerners clearly perceive similarity between the kiss of their own culture and the Southeast Asian smell-kiss. But aside from the flight of fantasy of the would-be exoticizing Westerner, the frequent packaging of both types of kisses into a single lexeme in Southeast Asian languages lends support to the idea that the comparative 'kiss' is not an ad-hoc category. For example, Modern Indonesian cium covers not only transitive 'smell' (5a), but also both the smell-kiss (5b) and the mouth-kiss (5c). These examples are all taken from the online version of the popular Indonesian magazine Tempo. The different 'kisses' denoted by (5b) and (5c) are clear from images accompanying the articles: with (5b) a man holds the hand of another to his nose and brow, while with (5c) the accompanying image shows the Pope's lips puckered and touching the foot of another.

(5) a. agar atlet Asian Games tak men-cium bau busuk kali may athlete Asian Games not AV-cium smell rotten stream 'The athletes of the Asian Games should not have to cium the stench of the stream'

b. Anggodo cium tangan Wisnu Anggodo cium hand Wisnu

'Anggodo ciums hand of Wisnu'

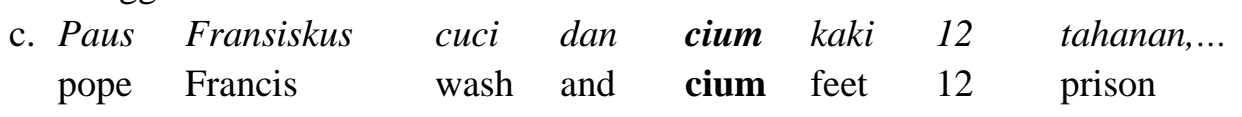

'Pope Francis washes and ciums the feet of 12 prisoners' 
That both a smell-kiss and mouth-kiss can be denoted by Modern Indonesian cium is further clear from the frequent inclusion of a body-part specifying the organ of kissing in nominal uses, as in the examples in (6).

(6) a. Jokowi lakukan cium-an hidung dengan tetua suku Maori
Jokowi do $\quad \begin{aligned} & \text { cium-NMLZ nose with elder tribe } \\ & \text { Maori }\end{aligned}$
'Jokowi does a nose cium with an elder of the Maori people'
b. Cium bibir di acara Resmi Negara, Presiden Filipina di-kritik
cium lip at event official state president Philippines UV-criticise
'Lip cium at official state function, President of the Philippines under fire'

Historically, Indonesian cium appears only to have referred to the smell-kiss, but, with exposure to western media, has been extended to the smell-kiss. This is a recurrent semantic extension in modern Southeast Asia. To name just a few instances: Khmer $t^{h} a \partial p$ is used for 'to sniff (e.g. a flower)' and for 'to kiss (formerly by touching someone's cheek with one's nose and sniffing; now used in the western sense') (Headley 1997); Tausug siyum typically refers to a kiss '[p]erformed by pressing one's cheek against the other person's cheek and nuzzling the other person with the nose while giving a sniff' but can be '[u]sed also to indicate any way of kissing' (Hassan et al. 1994). ${ }^{10}$ Such semantic extensions, arguably, point to a common perceptually-driven 'kiss' and support positing a comparative concept of 'kiss'.

If we take an extensionalist rather than intensionalist view, diversity should not be a hindrance to comparing lexical meanings, instead its study is the goal of research such as this.

\section{Conclusion}

This paper has investigated the semantic associations of verbs of olfactory perception. Whilst crosslinguistically rare, the colexification of verbs of smelling and kissing represents a robust association across the diverse ethno-linguistic groups of Southeast Asia. This reflects a shared cultural practice in which kissing involves an olfactory gesture, that is, the kiss is a so-called 'smell-kiss', a conventionalised gesture expressing greeting or affection in which the nose, rather than the mouth, is the primary organ of engagement.

While colexification of a transitive verb 'smell' or 'sniff' with 'kiss' is the most common pattern in Southeast Asia, other olfactory associations with kissing are found in several languages. For example, Thai (Tai-Kadai) hว̌sm is both a noun and a transitive verb meaning 'kiss' in addition to being an intransitive verb meaning 'to be fragrant, odoriferous, sweet smelling' (Haas 1964); Sgaw Karen (Sino-Tibetan) nrmu is a verb 'to kiss' and a noun 'a scent, a nice smell; a pleasant smell' (NA 2008) ${ }^{11}$; Prai (Austroasiatic) muh denotes both 'nose' and 'to kiss'. Such additional olfactory associations add to the picture of the smell-kiss as an areal feature of Southeast Asia.

Enfield (2005) observed that '[e]ven within the semiotic and cultural phenomena most closely tied to linguistic structure, little is known about the geographical distribution of variation.' This paper addresses this gap, with a case-study mapping the presence of smell/kiss colexification to give an outline of the geography of smell-kissing. This mapping is not exact, since an ethno-linguistic group can have smell-kissing without smell/kiss colexification. At the same time, smell/kiss colexification

\footnotetext{
${ }^{10}$ Tausug siyum is a Malay borrowing, but one that predates the period of modern film and electronic media.

${ }^{11}$ A reviewer suggests that such evaluative intransitive smell verbs being associated with kissing may be more common than depicted here. This may well be. The transitive smell verbs 'to smell' and 'to sniff', such as I focus on, do not appear to have these evaluative meanings (cf. Viberg 1983: 152-153).
} 
was never found in groups that historically lack smell-kissing. By charting not only the absence of smell/kiss colexification but also the distribution of suck/kiss colexification, a lexical pattern associated with the mouth-kiss, it could be seen that smell-kissing was not a cultural feature of groups beyond the northern fringe of the Southeast Asian linguistic area. Successive waves of language families moving southward into Southeast Asia, both on the mainland and in the insular regions, acquired smell/kiss colexification, indicating that the smell-kiss was an ancient feature that united the whole region. This study thus demonstrates the usefulness of lexical semantic typology in tracing the diffusion of cultural practices.

\section{Appendix: Sampled SEA languages}

Aceh, Agta (Dupaningan), Ahi, Akha, Alak, Angami (Kohima), Apatani, Arta, Atta (Pamplona), Baima, Balinese, Bantawa, Batak (Palawan), Batak (Karo), Batak (Toba), Biak, Bikol, Birhor, BodoGadaba, Bolinao, Bondo (Plains), Bontok, Brao, Bulang, Bunan, Burmese (Written), Car, Central Thai, Chadong, Chantyal, Chamorro, Cheng, Chepang, Chokri, Chong, Chrau, Cua, Chứt (Sách), Danaw, Darang (Taraon), Dehong, Dhao, Dumagat (Casiguran), Enggano, Ergong (Daofu), Ersu, Favorlang, Garo, Gta', Guiqiong, Hawu, Hewa, Hiligaynon, Hlai (Baoting variety), Iban, Idu, Ilocano, Indonesian/Malay, Jahai, Jarai, Javanese, Jeh (Yeh), Jinsha Dai, Juang, Kaili Ledo, Kaman (Miju), Kambera, Kapampangan, Kasong, Katu (Phuong), Kavalan, Kayan-Busang, Kei, Keme (Kemie variety), Kensiu, Khaling, Khamuang (Chiang Mai), Kharia, Khasi, Khezha, Khmer, Khumi, Kom Rem, Korku, Korwa, Kuki-Chin, Lahu, Lakkia, Lalo, Lamaholot, Langja Buyang, Lai (Falam), Larike, Laven (Jru'), Limbu, Lipho, Lisu (Central), Lolopho, Lotha Naga, Luang, Lushai (Mizo), Magar, Makasarese, Maleng (Kha Pong), Mang Ch, Manobo, Mansaka, Maonan, Mapun, Maranao, Maru (Langsu), Masbatenyo, Meithei, Mikir (Karbi), Mlabri, Mnong (Rölöm), Mon, Moyon, Mpi, Mulam, Muna, Muya (Minyak), Namuyi, Nancowry, Napu, Nasu, Newar, Noesu, Nung-Fengshan, Nyaheun, Nyah Kur (Central), Paiwan, Palauan, Palaung, Paliu, Pangutaran Sama, Pa-O, Pattani (Manchati), Pear, Phong, Pong, Qau Kelao, Qiang (Mianchi), Rejang, Riang (Sak), Rongga, Rumai, Samre, Sanchong Kelao, Sani (Nyi), Sangir, Santali, Sawai, Sedang, Semai, Shan, Sumi, Sobei, Sorbung, Southern Kam, Southern Tai (Songkhla), Spiti, Sre (Koho), Sunwar, Tai Khün, Tai Lü, Taijo, Tamang (Risiangku), Tangkhul, Tangut (Xixia), Tarieng, Tausug, Tboli, Temiar, Tetun, Thai (Korat variety), Thakali, Thao, Thavung, Tibetan (Sherpa, Helambu), Tiddim, Tina Sambal, Tsangla (Motuo), Turi, Tuwali Ifugao, Umar, Vietnamese, Wa, Waray, White Hmong, Xu, Xumi, Yakan, Yakha, Yi (Liangshan), Yogad, Zhuang-Longzhou

\section{References}

Abbi, Anvita. 2011. Dictionary of the Great Andamanese language. Port Blair: Ratna Sagar.

Adelaar, K.A. 1995. Borneo as a cross-roads for comparative linguistics. In The Austronesians: Historical and comparative perspectives, Peter S. Bellwood, James J. Fox \& Darrell T. Tryon (eds), 81-95. Canberra: Australian National University.

Bastian, Adolf. 1866 [2004]. A Journey in Burma (1861-1862). Singapore: White Lotus Press.

Blust, Robert \& Stephen Trussel. ongoing. Austronesian Comparative Dictionary, web edition. http://www.trussel2.com/acd/

Bourdet, L. 1912. Mercure de France: (sér. moderne): 99: 481.

Cense, A. A. 1979. Makasaars - Nederlands woordenboek. 's-Gravenhage: Nijhoff.

Clifford, Hugh \& Frank Athelstane Swettenham. 1894. A Dictionary of the Malay language. Taiping, Perak: Government Printing Offices.

Cort, Mary L. 1886. Siam: Or, The Heart of Farther India. New York: A. D. F. Randolph \& Company.

Crawfurd, John. 1852. A grammar and dictionary of the Malay language. London: Smith, Elder \& Co.

Dahl, Östen. 2008. An exercise in a posteriori language sampling. Sprachtypologie und Universalienforschung 61: 208-220. 
Danesi, Marcel. 2013. The History of the Kiss! The Birth of Popular Culture. New York: Palgrave MacMillan.

Eibl-Eibesfeldt, Irenäus. 1972. Love and Hate: The Natural History of Behavior Patterns. New York: Holt, Rinehart, and Winston.

Enfield, N. J. 2005. Areal linguistics and mainland Southeast Asia. Annual Review of Anthropology 34: $181-208$

Evans, Nicholas. 2010. Semantic typology. In The Oxford Handbook of Linguistic Typology, Jae Jung Song (ed), 504-533. Oxford: Oxford University Press.

Evans, Nicholas \& David Wilkins. 2000. In the mind's ear: The semantic extensions of perception verbs in Australian languages. Language 76: 546-592.

Ford, Clellan S. \& Frank A. Beach. 1951. Patterns of Sexual Behavior. New York: Harper and Row.

François, Alexandre. 2008. Semantic maps and the typology of colexification: Intertwining polysemous networks across languages. In From polysemy to semantic change: Towards a typology of lexical semantic associations, Martine Vanhove (ed), 163-215. Amsterdam: John Benjamins.

Garvan, John M. 1964. The Pygmies of the Philippines: Together with the Private Notes of Wilhelm Schmidt on the Above. Fribourg: Posieux.

Gil, David 2015. The Mekong-Mamberamo Linguistic Area. In N.J. Enfield \& B. Comrie (eds.), Languages of Mainland Southeast Asia, The State of the Art, 266-355. Berlin: De Gruyter Mouton.

Greenhill Simon J. \& Ross Clark. 2011. POLLEX-Online: The Polynesian Lexicon Project Online. Oceanic Linguistics 50: 551-559. https://pollex.shh.mpg.de/

Gregersen, Edgar. 1983. Sexual Practices: The Story of Human Sexuality. New York: Franklin Watts.

Haas, Mary. 1964. Thai-English student's dictionary. Stanford: Stanford University Press.

Haspelmath, Martin. 2007. Pre-established categories don't exist: consequences for language description and typology. Linguistic Typology 11: 119-132.

Haspelmath, Martin. 2010. Comparative concepts and descriptive categories in crosslinguistic studies. Language 86: 663-687.

Haspelmath, Martin \& Tadmor, Uri (eds) 2009. World Loanword Database. Leipzig: Max Planck Institute for Evolutionary Anthropology. http://wold.clld.org

Hassan, Irene and Halud, Nurhadan and Armour, Malcolm S. and Ashley, Lois and Ashley, Seymour. 1994. Tausug-English dictionary: Kabtangan iban maana. Jolo and Manila: Notre Dame of Jolo College and Summer Institute of Linguistics.

Headley, Robert K. 1997. Modern Cambodian-English dictionary. Kensington: Dunwoody Press.

Himmelmann, Nikolaus P. 2001. Sourcebook on Tomini-Tolitoi Languages: General Information and Word Lists. Canberra: Pacific Linguistics.

Jankowiak, William R., Shelly L. Volsche, and Justin R. Garcia. 2015. Is the Romantic-Sexual Kiss a Near Human Universal? American Anthropologist 117: 535-539.

Kalyanaraman, A. 1970. Aryatarangini: The saga of the Indo-Aryans. Volume 2. Bombay: Asia Publishing House.

Key, Mary Ritchie \& Comrie, Bernard (eds.) 2015. The Intercontinental Dictionary Series. Leipzig: Max Planck Institute for Evolutionary Anthropology. http://ids.clld.org

Kimoto, Yukinori. 2017. A Grammar of Arta: A Philippine Negrito Language. PhD thesis, Kyoto University.

Kirshenbaum, Sheril. 2011. The Science of Kissing: What Our Lips Are Telling Us. New York: Grand Central.

Lewin, Thomas Herbert. 1869. The Hill Tracts of Chittagong and the Dwellers Therein. Calcutta: Bengal Printing Company Limited.

List, Johann-Mattis, Thomas Mayer, Anselm Terhalle \& Matthias Urban. 2014. CLICS: Database of cross-linguistic colexifications. http://clics.lingpy.org

List, Johann-Mattis, Simon Greenhill, Cormac Anderson, Thomas Mayer, Tiago Tresoldi, Robert Forkel. 2018. Database of Cross-Linguistic Colexifications. Jena: Max Planck Institute for the Science of Human History. http://clics.clld.org

Man, Edward H. 1889. A dictionary of Central Nicobarese. London: W.H. Allen.

Matisoff, James A. 1992. Southeast Asian languages. In William Bright (ed.), International encyclopedia of linguistics, vol. 4, 44-48. New York: Oxford University Press. 
NA. 2008. Drum Karen English Student Dictionary. Drum Publication Group. http://www.drumpublications.org

Pawley, Andrew. 2007. Why do Polynesian island groups have one language and Melanesia many? Talk presented at the CNRS, Paris.

Reinach, Lucien de. 1911. Le Laos. Paris: Librairie orientale \& américaine, E. Guilmoto.

Schapper, Antoinette, Lila San Roque \& Rachel Hendery. 2016 Tree, firewood and fire in the languages of Sahul. In Lexico-typological approaches to semantic shifts and motivation patterns in the lexicon, Maria Koptjevskaja-Tamm \& Päivi Juvonen (eds), 355-422. Berlin: Mouton de Gruyter.

Shorto, Harry L. 1962. A dictionary of modern spoken Mon. London: Oxford University Press.

Spitzer, Leo. 1947. Essays in historical semantics. New York: Russell \& Russell.

Sweetser, E. E. 1990. From Etymology to Pragmatics. Metaphorical and Cultural Aspects of Semantic Structure. Cambridge: Cambridge University Press.

Urban, Matthias. 2010. 'Sun' = 'Eye of the Day': A Linguistic Pattern of Southeast Asia and Oceania. Oceanic Linguistics 49: 568-579.

Urban, Matthias. 2012. Analyzability and Semantic Associations in Referring Expressions. A Study in Comparative Lexicology. PhD thesis, Leiden University.

Whitehead, George. 1914. In the Nicobar Islands. London: Seeley Service \& Co. Limited.

Wlodarski, Rafael, and Robin I. M. Dunbar. 2014. What's in a Kiss? The Effect of Romantic Kissing on Mating Desirability. Evolutionary Psychology 12: 178-199.

Vanhove, Martine. 2008. Semantic associations between sensory modalities, prehension and mental perceptions: A crosslinguistic perspective. In From Polysemy to Semantic Change. Towards a Typology of Lexical Semantic Associations, Martine Vanhove (ed), 341-370. Amsterdam: Benjamins.

Viberg, Åke 1983. The verbs of perception: A typological study. Linguistics 21: 123-162. 